East African Medical Journal Vol. 81 No. 5 May 2004

DENTAL CARIES IN SIX, 12 AND 15 YEAR OLD VENDA CHILDREN, IN SOUTH AFRICA

A. S., Bajomo, BDS, MSc, M. J., Rudolph, BDS, MPH, MSc., and E. O., Ogunbodede, BChD, MPH, DDPH RCS, Division of Public Oral Health, School of Public Health, University of the Witwaterstrand, Johannesburg, South Africa

Request for reprints to: Dr. A. S. Bajomo, Division of Public Oral Health, School of Public Health, University of the Witwatersrand, Medical school, 7 York Road, Parktown 2193, South Africa

\title{
DENTAL CARIES IN SIX, 12 AND 15 YEAR OLD VENDA CHILDREN IN SOUTH AFRICA
}

\author{
A. S. BAJOMO, M. J. RUDOLPH and E. O. OGUNBODEDE
}

\begin{abstract}
Background: Oral diseases is still a major problem in most developing countries. Within the Republic of South Africa, there remains areas where few or no studies have been done on the oral health status. The emerging district health system with decentralisation of health services to address past inequity in health care in South Africa also provides compelling case for data collection at regional levels.

Objectives: To assess the prevalence and severity of dental caries of school children; determine the caries patterns of the study population and to provide useful data for the planning of oral health services in this region.

Design: Descriptive analytical study.

Setting: School children in the Donald Fraser Health District, Venda in the Northern province, Republic of South Africa.

Subjects/Methods: A total of 519 school children in the age groups 6, 12 and 15 years were examined by a calibrated examiner for dental caries using WHO diagnostic criteria. Both the schools, which were divided into rural and peri-urban locations and the children that participated were randomly selected.

Results: A mean dmft(sd) of 2.68(3.29) in six year olds and a mean DMFT (sd) scores of $0.61(1.50)$ and 1.26 (2.18) were recorded in the 12 and 15 year olds respectively. In the six year olds the upper anterior teeth showed highest susceptibility to caries, clearly indicating that black children suffer from early infant caries. At ages of 12 and 15 the mandibular molars were the teeth most affected. The decayed component constituted the main part of the dmft and DMFT scores. Ninety-nine percent of these lesions were untreated and the restorative care was almost nil.

Conclusion: An important finding was the doubling of the mean DMFT from the 12-yearolds to 15-year olds and the caries levels for all age groups was higher than the provincial average. The treatment required were mostly extractions and simple fillings, the majority of which could be managed by dental auxillaries using the Atraumatic Restorative Treatment Technique. This study indicates that preventive oral health measures should be implemented on the younger age groups in order to control dental caries.
\end{abstract}

\section{INTRODUCTION}

Oral diseases are still a major problem in most developing countries(1). In Africa, dental caries prevalence in the pre-school children seemed to be increasing in countries or parts of countries where there was an increase in sugar intake, while it remained low in countries where the poor economy restricted sugar intake(2).

Oral diseases, especially dental caries afflict more than $90 \%$ of the South African population. Dental caries are increasing in the major sectors of the population, especially the under-served, disadvantaged and urbanised communities(3).

Venda (the former independent state within south Africa) occupies the northeastern part of the Northern Province in the Republic of South Africa (R.S.A) (Figure 1). The present study was limited to Donald
Frazer health ward, which covers 3,130 square kilometers with a population of about 250,000 , thus a considerably large portion of the newly demarcated Vhembe health district. There is only one dentist in the public service for this population of 250,000. A suggested minimum recommended ratio is 1 dentist: 60,000 of the population(3).

The dmft/DMFT scores of urban black South African population was found to be 3.1 at $6,1.7$ at 12 , and 3.0 at 15 years of age(4). A large percentage of the score was untreated dental caries. Treatment for caries, in public dental facilities is in most cases extractions(5).

Eighty seven per cent of 12-year-old schoolchildren in the urban and rural areas of the former homeland of Gazankulu (now part of Northern Province) Republic of South Africa were caries-free(6). The reported 
fluoride levels ranged from $0-0.5 \mathrm{ppm}$ for community studied. These investigators further reported that rural males had the highest percentage of caries free children (96\%) and urban males the lowest (84\%). A similar trend was observed for 15 year olds(6).

It was reported that at the age of six years, the lower molar and the upper anterior teeth were most at risk, with the upper molar slightly more resistant(7). The lower anterior teeth were least affected by caries. At the ages of 12 and 15, the lower molars were slightly more susceptible than the upper molars, with the second molar less susceptible than the first molar(7).

The study of caries patterns of 12 year olds rural children in the Eastern Cape (formerly Transkei) found that the molar teeth in boys and girls accounted for more than $90 \%$ of all teeth affected; the first molars accounting for $50 \%$ and second molars $40 \%$ (8). For the total group (boys and girls combined), a greater number of first molars were affected than second molars. For girls, in both the maxilla and mandible, the second molars were more frequently affected than the first molars. Higher DMFT scores for females was also reported, suggesting that earlier eruption of the tooth in the female could account for higher caries experience(8).

Within the Republic of South Africa, caries prevalence and pattern appear to vary widely amongst the different sections of the population (9). The absence of epidemiological data, particularly in the rural communities of South Africa where almost $50 \%$ of the population reside, has contributed to the neglect of a preventive and curative plan for these areas(8). To date only Ramukumba et al. has conducted a study of the oral health status in Venda(10). In view of the historical, political and social changes in the R.S.A since 1991, and as a useful follow up to the Ramakumba et al. study, it was proposed to investigate the dental caries status of the schoolchildren in Venda.

Thus, the aim of the present study was to determine the prevalence of dental caries among schoolchildren in Venda. The objectives were: to assess the prevalence and severity of dental caries in 6,12 and 15-year olds schoolchildren, to determine the caries patterns of the study population and to provide useful data for the development and planning of oral health care services.

\section{MATERIALS AND METHODS}

Permission: Written permission was obtained from the Department of Health, the Regional Education Authority and parents or guardians of the pupils. Ethical approval was obtained from the committee for research on human subjects of the University of the Witwatersrand, Johannesburg.

Sampling: The stratified random sampling technique was adopted for this study. The Donald Frazer ward was randomly selected from the three wards in the former independent state of Venda. This was divided into peri-urban and rural areas. The criteria used in distinguishing between peri-urban and rural areas included lack of electricity and potable water and a distance of 50 kilometers from metropolitan area; all these were applicable to rural areas.

Two hundred and nineteen public schools in the health ward were divided into pre-primary, primary and secondary schools from which 12 schools were selected. Two preprimary schools each were randomly selected from all schools in the peri-urban and rural areas. Two primary and two secondary schools closest to the pre-primary schools were randomly selected. Thus six schools were represented in each of the peri-urban and rural areas (two pre-primary, two primary and two secondary schools). Fifty pupils in the 6,12 , and 15 age categories were randomly selected and examined at each of the pre-primary, primary and secondary schools respectively. A total of 519 school children were examined after 81 were excluded due to incorrect age of some of the pupils selected.

Clinical Examinations: The examination was conducted according to World Health Organisation (WHO) criteria, 1997. In recording caries severity the decayed, missing and filled tooth (dmft) index was used for six year olds and the Decayed, Missing and Filled Tooth (DMFT) for the 12 and 15 year olds. Dental caries was diagnosed by visual examination only. All the clinical examinations were conducted by one examiner and at the school premises, under a tree with natural day light. The child sat on a chair with the examiner behind using direct vision and a mouth mirror. The clinical findings were recorded by a nursing assistant.

Calibration: Initial calibration was done on extracted carious and caries free teeth which was repeated at one and three day intervals. Also during the actual examination, every tenth child was recalled at random to check for intraexaminer reproducibility which was above $90 \%$. The intraexaminer reproducibility was measured using Cohen's Kappa.

Statistical Analysis: All data collected were analysed using the SAS statistical programme on an IBM compatible micro-computer. The Mann-Whitney U-test was used to determine the differences between groups and sub-groups. Differences were regarded as significant at $\mathrm{p}<0.05$.

\section{RESULTS}

The number and percentages of school children examined by age, gender and location is presented in Table 1. The prevalence of caries in 6,12 and 15-year age groups were $61.8,21.8$, and $47.2 \%$ respectively (Table 2). In the six and 15 year age groups, females had a slightly higher prevalence of caries than males, which was reversed in the 12-year olds.

The DMFT (sd) scores in 12 and 15-year olds were $0.61(+1.50)$ and $1.26(+2.18)$ respectively and the differences were statistically significant (Table 3 ). The dmft (sd) for six year olds was $2.68(+3.29)$. No deciduous tooth was recorded as missing due to caries in six year olds. History and clinical judgment was used to distinguish between teeth missing due to caries or exfoliation (Table 4). 
Table 1

Number and percentages of school children examined by age, gender and location

\begin{tabular}{|c|c|c|c|c|c|c|c|c|}
\hline & \multicolumn{2}{|c|}{6 year olds } & \multicolumn{2}{|c|}{12 year olds } & \multicolumn{2}{|c|}{15 year olds } & \multirow[b]{2}{*}{ No } & \multirow{2}{*}{$\begin{array}{l}\text { Tota } \\
(\%)\end{array}$} \\
\hline & No. & $(\%)$ & No & $(\%)$ & No & $(\%)$ & & \\
\hline \multicolumn{9}{|l|}{ Gender } \\
\hline Male & 99 & 53.2 & 76 & 44.7 & 77 & 47.2 & 252 & 48.6 \\
\hline Female & 87 & 46.8 & 94 & 55.3 & 86 & 52.8 & 267 & 51.4 \\
\hline Total & 186 & 100 & 170 & 100 & 163 & 100 & 519 & 100 \\
\hline \multicolumn{9}{|l|}{ Location } \\
\hline Peri-urban & 94 & 50.5 & 79 & 46.5 & 86 & 52.8 & 259 & 49.9 \\
\hline Rural & 92 & 49.5 & 91 & 53.5 & 77 & 47.2 & 260 & 50.1 \\
\hline Total & 186 & 100 & 170 & 100 & 163 & 100 & 519 & 100 \\
\hline
\end{tabular}

Table 2

Number and percentage prevalence of dental caries by age, gender and location

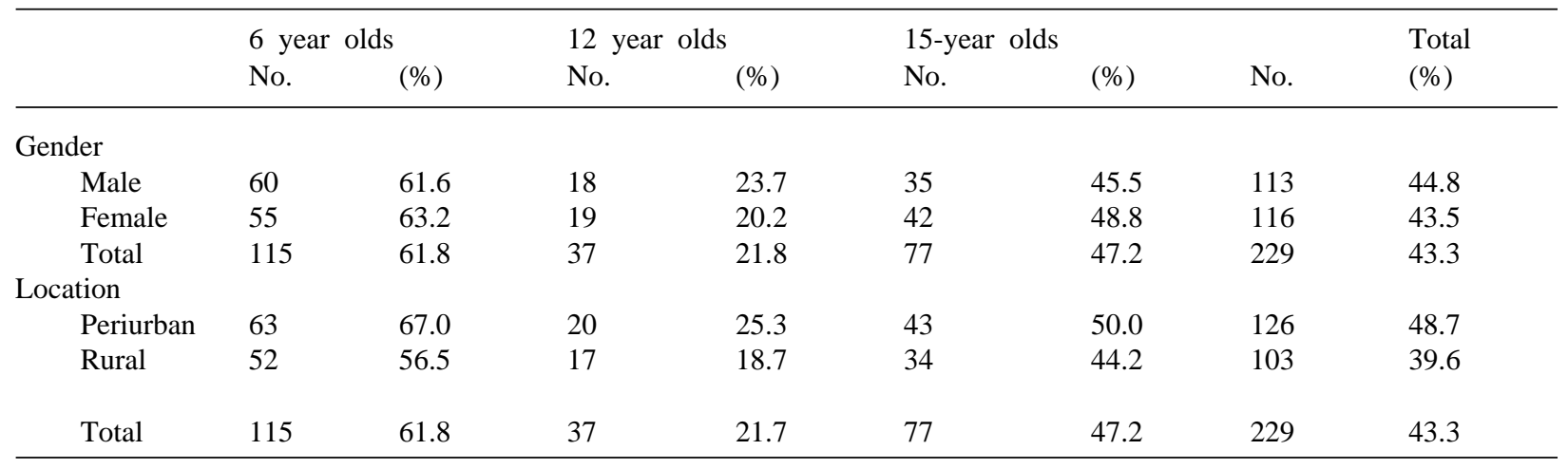

Table 3

Distribution of caries experience for 12 and 15 year olds

\begin{tabular}{llll}
\hline & $\begin{array}{l}12 \text { year olds } \\
\text { Mean }(\mathrm{sd})(\mathrm{n}=170)\end{array}$ & $\begin{array}{l}15 \text { year olds } \\
\text { Mean }(\mathrm{sd})(\mathrm{n}=163)\end{array}$ & $\mathrm{p}$-value \\
\hline DT & $0.55(1.33)$ & $1.11(1.97)$ & $0.02 *$ \\
MT & $0.02(0.19)$ & $0.08(0.42)$ & 0.097 \\
FT & $0.04(0.46)$ & $0.07(0.50)$ & 0.560 \\
DMFT & $0.61(1.50)$ & $1.26(2.18)$ & $0.01^{*}$ \\
\hline
\end{tabular}

Six year olds were not included in the analysis due to the difference in the indices used (dmft versus DMFT)

* Significant at p-value $<0.05$ 
Table 4

Caries experience for 6, 12 and 15 year olds by location

\begin{tabular}{|c|c|c|c|c|}
\hline & $\begin{array}{l}\text { Peri-urban } \\
\text { Mean (sd) }\end{array}$ & $\begin{array}{l}\text { Rural } \\
\text { mean(sd) }\end{array}$ & $\begin{array}{l}\text { Total } \\
\text { mean(sd) }\end{array}$ & p-value \\
\hline 6 years & $(\mathrm{n}=94)$ & $(n=92)$ & $(\mathrm{n}=186)$ & \\
\hline $\mathrm{dt}$ & $3.39(3.83)$ & $1.93(2.40)$ & $2.67(3.28)$ & $0.02 *$ \\
\hline $\mathrm{mt}$ & $0.00(0.00)$ & $0.00(0.00)$ & $0.00(0.00)$ & 1.00 \\
\hline $\mathrm{ft}$ & $0.02(0.00)$ & $0.00(0.00)$ & $0.01(0.15)$ & 0.32 \\
\hline $\mathrm{dmft}$ & $3.41(3.80)$ & $1.93(2.40)$ & $2.68(3.29)$ & $0.01 *$ \\
\hline 12 years & $(\mathrm{n}=79)$ & $(\mathrm{n}=91)$ & $(n=170)$ & \\
\hline DT & $0.75(1.66)$ & $0.37(0.95)$ & $0.55(1.33)$ & 0.27 \\
\hline MT & $0.05(0.27)$ & $0.00(0.00)$ & $0.02(0.19)$ & 0.06 \\
\hline FT & $0.08(0.68)$ & $0.00(0.00)$ & $0.04(0.46)$ & 0.28 \\
\hline DMFT & $0.88(1.92)$ & $0.37(0.95)$ & $0.61(1.50)$ & 0.18 \\
\hline 15 years & $(n=86)$ & $(\mathrm{n}=77)$ & $(n=163)$ & \\
\hline DT & $10.8(2.05)$ & $1.14(1.89)$ & $1.11(1.97)$ & 0.83 \\
\hline MT & $0.13(0.56)$ & $0.03(0.16)$ & $0.08(0.42)$ & 0.12 \\
\hline FT & $0.14(0.69)$ & $0.00(0.00)$ & $0.07(0.50)$ & 0.06 \\
\hline DMFT & $1.35(2.40)$ & $1.17(1.91)$ & $1.26(2.18)$ & 0.71 \\
\hline
\end{tabular}

*Significant at $\mathrm{p}$-value $<0.05$

Figure 1

Map of Southern Africa showing the location of Venda

Figure 2a

Caries pattern according to tooth type in six year olds 
Figure 2b

Caries pattern according to tooth type in 12 year olds

Figure 2c

Caries pattern according to tooth type in 15 year olds

In all the age groups, the prevalence of caries was consistently higher in the peri-urban locations. In both the peri-urban and rural subjects caries doubled from age 12 to 15 years(Table 4).

The mean dmft/DMFT of 6, 12, and 15-year olds was higher in peri-urban than rural areas, as well as the individual components of the index, except in the decayed component of 15-year olds. More than $90 \%$ of the total mean dmft/DMFT comprised of the decayed component in all the age groups. In six year olds there were significant differences between the peri-urban and rural areas in the mean $\mathrm{dmft}$, as well as the decayed component of the dmft $(p<0.05)$. No restorations were recorded in any of the age groups in rural areas (Table 4).

Figures II $\mathrm{a}, \mathrm{b}$ and $\mathrm{c}$ show the caries patterns according to tooth type in 6,12 and 15-year olds. In six year old maxillary teeth, caries involvement of the molars and the incisors was almost equal. In the mandible, the molar teeth were predominantly affected, the first primary molar teeth and the second primary molar were almost equally affected. In the 12 and 15 year olds, both in the maxilla and mandible, the molar teeth were the most frequently affected; the first molar in the 12 year olds but the second in the 15 year olds.

\section{DISCUSSION}

The percentage prevalence of caries of $61.8,21.8$ and $47.2 \%$ amongst the 6,12 and 15 year olds respectively in the present study was lower than in the six year olds and considerably lower in the 12 and 15 year age groups compared to black urban metropolitan South Africans (11) which showed percentage prevalence of 66.2, 54.0 and 70.7 respectively, despite comparable or even higher water fluoride levels in these metropolitan areas. This urban/rural difference may be due to socioeconomic factors.

The fluoride content of the water from the different sources in the Donald Frazer Health Ward varied from 0.01-0.04. This is very low considering the WHO recommended level of 0.51-1.0ppm (12) and the current recommended fluoride levels of $0.5-0.7$ for South Africa (13) and thus is unlikely to have accounted for the observed low caries status in this region. The low caries status in the population may largely be attributable to the low socio-economic status of the population.

In rural areas such as Venda in the Northern province the per capita income of the people is less than R6000 per year compared to the national average of up to R12000, and the staple diet is maize ('Mealies') 
which is produced by the villagers themselves. The traditional method of preparation of the maize has been reported to yield less cariogenic "mealies" compared to the modernized form of maize preparation(7). This may account for the relatively low caries experience observed among this population. The peri-urban population had a relatively higher mean dmft/DMFT in all the age groups studied. The relatively low caries rate of rural populations in comparison with urban populations is consistent with other studies previously reported from many African countries(10,14,15).

It is indeed generally acknowledged that in the rural areas there is limited access to sugar and to sugar containing food and drinks, mainly because these food and beverages are not affordable to the rural populace(16). The higher caries levels in urban population groups have been attributed to the change of consumption from traditional food, for example "mealies" and vegetables to those which contain increased sugar content(17). It is often stated that as a result of the isolation of rural communities and because of their way of life, they would not be exposed to the causative factors of caries found in urban communities(18). It was reported that in developing countries, children from higher socioeconomic groups, often residing in the urban and more affluent parts of the country, have more dental decay than children from lower socioeconomic groups often residing in the rural $\operatorname{areas}(2)$. This seems to apply also to the peri-urban/ rural differences in this study. Similar differences were also reported in a study amongst Swaziland in six and 12 year old children(15). Similarly, the recent report of the national children oral health survey conducted during 1999-2002 showed that Northern province - the most rural province, consistently recorded the lowest levels of caries experience in the country(19). It is however pertinent to note that caries experience in the region under study within the province showed considerably higher levels of caries for all age groups. A caries prevalence of $61.8 \%$ among six year olds in this region is about $50 \%$ higher than the provincial average of $37.2 \%$ previously reported(19). This observation underscores the importance of studies of this nature in adequately planning for services at local levels.

The WHO set a goal for the year 2000 whereby the caries prevalence in five year old children should not be more than $50 \%(12)$. The present study found a prevalence of $61.8 \%$ in the primary dentition of six year olds, which suggests that, had five year olds been included, the prevalence may have been higher than the $50 \%$ goal. This concurs with the view that caries in the primary dentition is a major public dental health problem(18). A higher prevalence of caries in the primary dentition than in the permanent dentition was also reported in children in the South East Asia(2). Efforts need to be made to limit this high prevalence of caries through effective preventive measures. A striking finding from this study was the doubling in percentage prevalence of caries levels from the 12 to the 15 year old groups. This supports the view that the younger age groups should be a focus for preventive programmes in South Africa(15).

The DMFT scores of 2.68, 0.61 and 1.26 for 6 , 12 and 15 year olds respectively were consistently low for all the age groups. A DMFT of 0.61 for the 12 year olds in this study, was two and a half times lower than the DMFT of 1.7 in the same age group amongst a South African black metropolitan population(7). This DMFT of 0.61 at age 12 was much lower than the DMFT goal of three set by the WHO for the year 2000 . Notwithstanding the possibility that these figures may be under-estimated (based on recommended visual criteria), the school population of Venda falls within the category of communities where an attempt is needed to prevent the DMFT from rising above the present levels.

DMFT scores of 1.04 and 0.44 in peri-urban and rural areas of Venda was reported amongst the 12 year olds respectively(10). In comparison, the present study showed a DMFT of 0.88 in the peri-urban areas and 0.37 in the rural areas. The caries experience in 1991 was slightly higher in the urban population but comparable to the caries prevalence in the rural population. The current data showed that there has been little change in oral health status, being only slightly higher in peri-urban areas in spite of a lack of preventive programmes for the rural populations. The urban population may have benefited from some improvements in terms of dental education, facilities and treatment.

In a study of a 12 year old black population group living in the former Gazankulu 'Homeland' (now part of the district under study in Northern Province); DMFT scores of 0.3 and 0.13 were recorded for the peri-urban and rural population respectively (6) and in this study, with DMFT of 0.88 and 0.37 respectively in the peri-urban and rural areas. This may be an indication of a gradual rise in caries prevalence levels amongst the black population in this region. Thus, there is a need to take proactive action to control or prevent the rising levels of caries.

The decayed component of the dmft/DMFT score was the highest for all the age groups (Table 4). This is in agreement with all the studies conducted among the black populations of South Africa(7,9,20). As in other studies in rural South Africa $(8,18)$ few extractions and hardly any restorations were observed, and the common natural path for carious teeth was disintegration in situ. This observation supports the statement that more than $90 \%$ of dentinal lesions in African countries are untreated(21). This reflects the minimal amount of dental treatment received by the children, which may be explained by the current unfavourable dentist/ population ratio, inadequate facilities and resources as well as poor dental health awareness in the general population(22). More trained personnel are required for 
basic oral care which could address the many untreated dental lesions(1).

The missing component of dmft/DMFT was low in all age groups compared to the decayed component. This further supports the statements that the dentinal lesions in African countries go untreated. This is also similar to the other results among black populations in South Africa $(7,10)$. The Venda study showed that more extractions were done in the peri-urban compared to the rural areas, due to dental services being more readily available in peri-urban settlements.

It was further shown that in the rural population there was no restorative care but in the peri-urban population groups there was some evidence of minimal restorative care. A low level of filled teeth has been reported from other studies $(7,8)$. This may be explained by the limited financial and human resources available as well as costs of transport and lack of accessibility to facilities.

The lower second primary molar was the tooth most at risk amongst the black metropolitan six year olds group(7). This is in contrast to the findings of the current study which showed a similar susceptibility of the lower first and second primary molar. It was demonstrated that the upper first molar was slightly more resistant to caries, compared to the second upper and lower molars(7) which was supported by findings in this survey. Also for six year olds, the upper interior teeth were more affected than earlier reported, while the lower anterior and upper canines were the most resistant to caries, which concurs with the findings of this study(Figure 2c).

At the ages of 12 and 15 the mandibular molars were most affected, while the lower anteriors were the least affected by caries. This finding is in agreement with previous studies $(6,14,23)$. It was shown that in 12 year olds pooling maxillary and mandibular data for both arches, a greater number of first molars were affected than second molars(6), which this study confirmed.

There was no gender differences in caries experience in any of the age groups. This was in contrast with the results of a study carried out in Transkei (a former independent homeland in South Africa) amongst the 12-year olds(6) which showed a higher caries experience for females. It was suggested that the earlier eruption time of the permanent teeth in the females may have been responsible for the higher caries experience(6). A study in Zimbabwe also reported higher levels of caries in females compared to the males(14). Results of this study is in accordance with the findings, which showed no significant differences in the percentage caries prevalence between males and females in comparable age groups examined(18).

\section{CONCLUSIONS}

The present study demonstrated relatively low levels of caries experience for all the population groups studied, but there was a large amount of untreated carious lesions. The caries experience in the region studied was considerably higher than that of the provincial average in which it is located, thus highlighting need for data collection at local levels. The implications in terms of personnel and resources required to provide care for the large amount of untreated carious lesions especially among the six year olds, cannot be underestimated especially within the context of other competing health priorities for this socioeconomically disadvantaged population.

\section{RECOMMENDATIONS}

Oral health education and treatment programmes should be implemented in primary schools, and these programmes may possibly be managed and facilitated by oral hygienists who can place fissure-sealants and simple restorations such as the relatively inexpensive Atraumatic Restorative Technique (ART).

Those with untreated active caries requiring treatment for pain and sepsis can be referred to public dental clinics for conventional restorative treatment and extractions. Training in oral health education should also be provided to the community health workers and school teachers who could in turn educate the children and thus hopefully sustain the programmes. However, such programmes should be done within the conceptual framework of health promotion and should include issues related to school policy such as creating a suitable health promoting school environment, encouraging community involvement through school governing bodies, improving personnel development and providing resources such as materials and posters.

Implementation of a surveillance system to monitor patterns of oral disease at local or district levels and evaluate impact of intervention programmes should be given priority.

\section{ACKNOWLEDGEMENTS}

To Mrs E. Viljoen for the Statistical analysis. We are also grateful to V. Netshandama and M. Tshifhiwa for their assistance with the recordings during the clinical oral examination. The authors also thank Dr. O. A. Ayo-Yusuf of the University of Pretoria for his invaluable advise, and the teachers and children of all schools in Thohoyandou and Mutale districts, for their willing assistance and cooperation which made this study possible. 


\section{REFERENCES}

1. Attin, T., F. N., Mbiydzemo, I., Villard, A. M., Kielbassa, and E. Hellwig. Dental status of School Children from a rural community in Cameroon. J. South Afr. Dent. Asso. 1999; 54:145-148.

2. Holm, A. K., Caries in the Preschool Child: International trends. J. Paed. Dent. 1990; 18:291-295.

3. Department of Health. National Oral Health Policy for South Africa, 1997.

4. Department of Health. National Oral Health Survey, South Africa 1994.

5. Department of Health. Community services for dentist in the Republic of South Africa 1999.

6. Chikte, U.M.E. and Rudolph, M.J. Caries patterns in Gazankulu. J. Dent. Res. 1990; 69:1087.

7. Du Plessis, J. B., Hodges, N., Pienaar, V., and D.R., Oosthuizen, D.R. The dental caries status of black population in the major metropolitan areas of the Republic of South Africa. In: National Oral Health Survey South Africa. 1988/ 89. ed. Van Wyk, PP. 33-44, 1994.

8. Chikte, U. M. E., Gugushe, T. S., Rudolph, M. J., and Reinach. R.G. Dental caries prevalence and CPITN of 12-year-old rural School Children in Transkei. J. Dent. Assoc. South Afr. 1990; 45:245-249.

9. Cleaton-Jones, P. E., and Hargreaves, J. A., Dental caries of 11 to 12-year-old South African Children and WHO guidelines for the year 2000. J. Dent. Assoc. South Afr. 1989; 43:357-359.

10. Ramukumba, A. N., Rudolph, M. J., and Chikte, U. M. E.. Oral Health in Venda: Dental caries of 6 and 12 year-old School children. J. Dent. Res. 1991; 70:845.
11. Department of Health. National Oral Health Survey, South Africa, 1988/89.

12. World Health Organization. Primary health care. WHO, Geneva, 1990

13. Department of Health. Regulation Gazettee, 2000.

14. Chironga, L., and Manji, F., Dental caries in 12-year-old urban and rural Children in Zimbabwe. Comm. Dent. Oral Epid. 1989; 17:31-33.

15. Gugushe, T. S., and du Plessis, J. B., Regional urban-rural distribution of dental caries in Swaziland. J. Dent. Assoc. South Afr. 1998; 53:409-412.

16. Sheiham, A., Sucrose and dental caries. Nutr. Hlth. 2000; 5:25-29.

17. Sheiham, A., Why free sugars consumption should be below $15 \mathrm{~kg}$ per person per year in industrialised countries: the dental evidence. Brit. Dent. J. 1991; 171:63-65.

18. Carstens, I. L., Louw, A. J., and Kruger, E., Dental status of rural school children in a suboptimal fluoride area. J. Dent. Assoc. South Afr. 1995; 50:405-411.

19. Department of Health. National children's Oral Health Survey South Africa, 2003.

20. Louw, A. J., Carstens, I. L., and Hartshorne, J. E., A caries preventive programs for Robertson School Children-baseline data. Dent. Assoc. South Afr. 1991; 46:463-465.

21. Thorpe, S., Oral Health, reaching out to the year 2000. Keynote address at the 7th IADR -meeting of the East and Southern Africa section, Harare, 1992.

22. Ng'ang'a, P. M., Epidemiological and experimental studies pertaining to orthodontic treatment in children in Nairobi, Kenya. Thesis, 1996.

23. Ng'ang'a, P. M., and Valderhaug, J., Dental caries in primary school children in Nairobi, Kenya. Acta. Odontologica. Scandinavica. 1992; 50:269-272. 